\title{
Human security and sexuality in the IPPF Africa Region
}

\author{
Patrick Orotin, Cheick Ouedraogo, Tewodros Melesse \\ (International Planned Parenthood Federation Africa Regional Office, Nairobi 00100, Kenya)
}

\begin{abstract}
The influence of human security components on Sexual Reproductive Health and Rights (SRHR) of individuals was explored in four sub-Saharan Africa countries of Angola, the Democratic Republic of Congo, Liberia and Uganda from November 2008 to April 2009. The present results suggest that the major threat to human security is the competing economic demands that make it difficult for the population to prioritize reproductive health services in their household budgets. This study concludes that there are potential benefits of human security approaches for furthering the goals of SRHR initiatives, in line with the principles and guidelines expressed in the Maputo Plan of Action and the Millennium Development Goals (MDGs). The results of this study suggest that IPPF Africa Region can start to prioritize economic security, community security and health security which have greatest impact on the reproductive health of the sub-Saharan African population. The key lesson learnt is that the effective use of family planning services mitigates the effects of other human insecurities, including economic, food, and health insecurities as its application in the families will reduce family size and demand on available resources.
\end{abstract}

Key words: human security; reproductive health and rights; millennium development goals; Maputo plan of action; sub-Saharan African population; IPPF Africa Region

\section{Introduction}

The concept of human security and its linkages to sexual health is gaining importance in human development. Human security refers to analysis of relationships between poverty, accountability and vulnerabilities (UNDP Report, 1994). Recently, human security has been enlarged to include the following aspects of human life; economic, food, environmental, personal, community, political and health securities. For example, the millennium development goals (MDGs) cannot be achieved without addressing sexual rights of PLWAs; For basic human

\footnotetext{
* Acknowledgements: The authors wish to thank IPPFAR Office management and advisors, member association staff and development partners in the DRC, Angola, Liberia and Uganda for their excellent support to this complex study. The authors wish to acknowledge the invaluable contribution and assistance provided in each of the target country by the member associations' directors and staff. The authors would like to thank them for their active participation in the research study and assistance with logistical support to the team in each country which helped to facilitate a smooth field process. Similarly, the authors wish to recognise the important contributions from governmental and non-governmental organisations in providing useful information for the study. Their effective collaboration helped in better understanding the influence of human security in each individual country which informed the study findings. Finally, the authors are immensely grateful for the willing participation of clinic staff, volunteers and clients at IPPFAR member associations in providing invaluable information and references to the team. Also for setting up appointments for the team in advance and ensuring successful implementation of the study in each country.

Patrick Orotin, social science researcher, International Planned Parenthood Federation Africa Regional Office; research fields: community development and reproductive health.

Cheick Ouedraogo, Ph.D., public health researcher, International Planned Parenthood Federation Africa Regional Office; research field: reproductive health.

Tewodros Melesse, economist, International Planned Parenthood Federation Africa Regional Office; research field: reproductive health.
} 
rights, political security need to be guaranteed; Sexual health and rights can only be guaranteed through respectful approach to sexuality; Without mechanisms to address uneven distribution of resources, poverty and disempowerment, there cannot be an enabling environment to promote universal access to sexual reproductive health and rights (SRHR). Thus, holistic approaches to health and development, including the concept of human security will provide a framework within which to view Africa's development. Human security forms an important part of people's well being, and thus a need for stock-taking what is known for provisional guidance on the development of human security within the SRHR programming, and in order to identify issues in need of resolution. In response to this, a study was conducted between November 2008 and April 2009 in the Democratic Republic of Congo (DRC), Angola, Liberia and Uganda, which are selected for their worst experience in human insecurity.

\subsection{Objectives of the study}

This study sought to: (1) derive lessons from policy initiatives and interventions that include sexual reproductive health and rights (SRHR) as an element of human security, and (2) to initiate discussion within IPPF Africa Region towards human security policy formulation that can be translated into guidelines for sexual reproductive health and rights (SRHR) programming within the sub-Saharan Africa.

\subsection{Research questions}

The key research questions addressed by this study were: (1) How has human security been interpreted and used within the context of IPPF Africa Region (IPPFAR) and other partners work? (2) What approaches, including policy initiatives have been used to promote human security in the IPPFAR? (3) What are the documented linkages, outcomes and impacts of human security on Sexual Reproductive Health and Rights? (4) What are the lessons learnt regarding management of human security issues from the global and regional perspectives? (5) What approaches of human security are likely to be effective under the conditions prevailing in Sub-Saharan Africa (SSA) and what are pitfalls to avoid? (6) How can this study allow IPPFAR to operationalize TICAD and other agreements that incorporate human security?

\section{Methodology}

An exploratory study with a qualitative design was applied. Purposive samples were drawn from existing country data bases of NGOs and agencies involved in human security related activities. Personal interviews were used to obtain primary data and desk review to obtain secondary data. The data collection methods included: key informant interviews, group interviews, on-site observations and success stories gathered using the Most Significant Change (MSC) methodology. A total of 53 key informant interviews were conducted with partners and stakeholders in Angola, the DRC, Liberia and Uganda, and they were used to understand in-country policy initiatives and also derive recommendations about the application of human security in SRHR programming. Two to three clients' centred focus group discussions were conducted with groups of female, male and youth community members, and were used to derive opinions, recommendations and lessons learnt about the application of human security approaches in SRHR programming. The MSC approach captured and ranked individual stories according to how individuals felt about the outcome of the problem and what was impacting to their lives in as far as SRHR is concerned. Data was analysed by themes through content analysis and documentation of MSC stories. The following sections present the key results and conclusions from the application of human security from the 
global, regional and national perspectives.

\section{Results and discussion}

\subsection{Current interpretation of human security}

From the study, human security (HS) incorporates immediate threats that people face in their day to day lives, like where to get food, freedom from crime, safety from hunger, disease and repression, protection from sudden and hurtful disruptions in the patterns of daily life (UNDP Report, 1994). It is broken into seven categories: economic security, food security, health security, environmental security, personal security, community security and political security. The results from the study indicate that human security has been incorporated into international development dialogues and agreements like the 2005 United Nations World Summit, which committed to "discussing and defining the notion of human security in the General Assembly" (UN Report, 2005), and the 2008 Tokyo International Conference on African Development IV (TICAD IV), which set as its second priority, "ensuring human security, including the achievement of the MDGs and the consolidation of peace and democratization". The most powerful attribute of human security is its expansiveness and inclusiveness, which provides a framework within which almost all human development efforts can be characterized (Commission on Human Security, 2003). It provides a framework for the analysis of populations as seen by the National Human Development Reports of Afghanistan 2004 (UNDP Report, 2004). It has also been used by policy makers to set priorities for development; for example, in a survey conducted in 2002/2003, Latvians identified income uncertainty and access to healthcare as the two most pressing threats to their security (Jolly, et al., 2007).

\subsection{Current status of the application of human security approaches in SRHR in IPPF Africa Region}

Human security (HS) approach has generally not been adopted by IPPFAR member associations in the countries visited. Efforts to integrate human security approaches have mainly been reactive to existing socio-economic realities rather than a pro-active, conscious effort to focus on human security as a model for implementing SRHR programmes. The following sections present the current linkages between human security components and sexual reproductive health and rights (SRHR).

\subsubsection{Economic security and SRHR}

From the study, economic insecurity appears to be the most pervasive form of vulnerability facing communities within the IPPFAR. Competing economic demands make it difficult for SRHR target groups to prioritize reproductive health services in their household budgets, as demonstrated by the story (A story of a lady focusing on economic insecurity in the Democratic Republic of Congo) below:

This is a story of a lady in her early 40s, who lives in Kinshasa, DRC, and currently has 16 children as a result of 2 triplet pregnancies, 4 twin pregnancies and 2 single pregnancies. She is a stay-at-home mother, and her husband is a teacher in a primary school in Kinshasa. At the time when the consultant met with her, she had come to the clinic to collect Contraceptive pills. When she was asked how come she has been pregnant so many times, she said that she has been using pills for a long time, but sometimes forgets to take them. When asked why she doesn't use the contraceptive implant, her response was:

"I know of it, but it is too expensive, we cannot afford to use it".

\subsubsection{Food security and SRHR}

The major impact of food insecurity on SRHR is that because people in low income countries spend almost half of their incomes on food, the amount of money available for other needs, including reproductive health is 
reduced (Trostle, 2008). It is also linked to risky sexual behavior, especially among women, in that food, insufficiency is associated with inconsistent condom use with a non-primary partner, intergenerational sexual relationships, and lack of control in sexual relationships (Weiser, et al., 2007).

\subsubsection{Environmental security and SRHR}

Environmental risks such as air pollution, access to clean water and desertification are threatening the livelihoods of the population (WHO Report, 2009). The most common environmental challenge experienced in the countries visited was poor sanitation, especially in the slum or congested areas, where many people have to share very few toilets. A respondent from the Reproductive Health Uganda clinic in the resettlement camp in Gulu in Northern Uganda had this to say:

"Congestion and poor sanitation also predisposed camp residents to sexually transmitted diseases. For example, residents are forced to share tiny bathrooms which encourage the spread of infectious diseases”.

\subsubsection{Health security and SRHR}

Health security entails that people have access to the highest attainable level of health. A respondent from one the government health centre in Uganda had this to say:

"We are always talking about poor attitudes of the health workers. But what brings about this poor attitude of the health workers? They go to the health centre, there are no gloves, there is no water; you know, there is no lighting! How are they going to work? For me, I feel that unless government puts more resources to reproductive health, we are not doing much, because right now, we go to the communities, we are telling people; it is good for you to go to health centers. The women will walk a very long distance to the health centers. They will find someone there who is very rude, because her child has no food, so how are we helping ourselves?”

This picture is no different from what is seen in other countries in Sub-Saharan Africa (SSA), which according to WHO report (2008), have health insecure populations characterized by underfunding of the health sector. Government expenditure on health in SSA in 2005 was 8.8\%. Per capita expenditure on health is 112 USD in SSA and it goes lower in post conflict countries, e.g., Liberia—41 USD, Angola—41 USD and DRC-12 USD.

\subsubsection{Community security and SRHR}

The most prevalent human insecurity community practices that have impact on SRHR of people in the SSA are:

(1) Female genital mutilation (FGM), which is widespread in Liberia, but localized in Uganda to only a few tribes in Eastern Uganda. Depending on the culture, it is practiced as an initiation into womanhood, and for cultural identity. It is also used to control sexuality of girls. FGM results in a number of negative SRHR consequences, including: damage to the external genitalia, reproductive tract infections, pelvic infections, infertility, painful sexual intercourse, traumatic childbirth, increased risk of HIV infection due to the instruments used and the damage to the tissue and psychological illnesses.

(2) In Angola, the DRC, Liberia and Uganda, respondents reported that due to the displacement of the people caused by the wars, many families were separated, and this has greatly weakened the family structures. A family is a very important institution in the African culture where girls are brought up by the entire community and not just the nuclear family. In DRC, for example, it was reported that there was an increase in juvenile delinquency and promiscuity of girls (DRC DHS Report, 2007).

(3) In Northern Uganda, some members of the community feel that women should be allowed to give birth 
naturally and, therefore, they should not use family planning methods and believe it is their right to produce as many children as they want (DHS Report, 2006). Some also feel that since many people died during the war, they must have many children to replace those that died.

In all the countries visited, the gender dynamics reported were such that men are considered to be superior to women, who must obey what they say. In the words of a gentleman in the IDP resettlement camp in Northern Uganda:

“You are a man, since you've grabbed the woman from her home, she should be under your authority and whatever you say, she has to follow, whether it is favourable or not”.

\subsubsection{Political security and SRHR}

One of the most important aspects of human security is that people should be able to live in a society that honours their basic human rights, in this case, that is the right to the highest standard of reproductive health. In all countries visited, there appears to be recognition by the government of the importance of SRHR of the people. The importance of SRHR is highlighted in the poverty reduction strategy papers (PSRP) of Uganda (Uganda PRSP, 2004-2008), Liberia (Liberia PSRP, 2008-2011), DRC (DRC PRSP, 2007) and Angola (Angola PRSP, 2004), which are at various stages of implementation. In Liberia, it had not yet begun. Much of the Poverty Reduction Strategy Paper was mainly aimed at reducing maternal mortality (Liberia, PSRP, 2008-2011).

\subsection{Initiatives that are used to promote human security and SRHR}

\subsubsection{International level initiatives}

Human security network (HSN), launched in 1999 at a Ministerial meeting in Norway, with Mali in Africa as a member, provides a platform for comprehensive response to HIV/AIDS prevention and care as highlighted in joint Workshops on Comprehensive Responses to HIV/AIDS Prevention and Care in Nairobi, Kenya on June 2005; in Geneva on 25 July 2005; in Gaborone, Botswana in November 2005 (OECD Vol. 2, 2006). The objective of the workshops was to exchange best national practices in improving the interface between policies and programmes, including community good practices at the national and international levels.

3.3.2 National and sub-national level initiatives

(1) Economic security and SRHR

In reproductive health Uganda (RHU), a new strategic plan (2009-2013) incorporates the issues of food, economic and environmental security. Apart from implementing its core SRHR programmes, RHU also refer clients to organizations that address other vulnerabilities, e.g., in Bwaise, a Kampala suburb, sex workers are referred to a youth development project that provides vocational training. In Fort Portal, a town in Western Uganda, women clients are linked to a GTZ funded project that promotes economic security for women. However, all these initiatives were not undertaken under the umbrella of human security per se, but as a result of the recognition that they must be addressed if reproductive health goals, which is their core mandate, is to be achieved.

(2) Environmental security and SRHR

Reproductive Health Uganda (RHU) was involved in community sanitation sensitization on proper hygiene in the IDP resettlement camps in Northern Uganda and in the slums in Kampala. They were unconsciously operationalising the human security approach in their SRHR programming.

(3) Political security and SRHR 
Advocacy campaigns in partnership with the Network of African Women Ministers and Parliamentarians (NAWMP) in Uganda carried out campaigns geared towards increasing attention to reproductive health and reproductive health commodity security among members of parliament. The Family Planning Association of Liberia (FPAL) was also in the process of including these two issues in their advocacy agenda, signifying the importance of political security and involvement of politicians in promoting health security as a key component of human security.

(4) Community security and SRHR

Community security is a very difficult issue to tackle, because many of these initiatives are intertwined in it. A men’s MSC story (Men’s MSC story on community health, personal and community security) below illustrates how it is being applied:

\footnotetext{
"We have constituted ourselves into different groups. Men, youth and women who have been trained by Reproductive Health Uganda.... These groups sensitize camp residents on various issues, including sexually transmitted diseases (STDs) and domestic violence. For example, training on how to prevent STDs has helped a lot; the level of drunkenness has gone down and the incidence of wife beating has reduced.”
}

\subsection{Influential factors for the human security approach in the IPPF Africa Region}

\subsubsection{Enabling factors}

(1) IPPFAR can expect a positive response to human security approach from other NGOs. For example, a programme that was providing farm inputs to people in resettlement camps in northern Uganda recognized the impact that HIV/AIDS was having on the farming community, as well as the way the spiraling population growth was increasing the food insecurity in the community. This is important, because when IPPFAR decides to operationalize the approach, they will find a receptive NGO and government community.

(2) The IPPFAR member associations have the capacity to penetrate the communities in which they work at the national and local levels. This is mostly due to the good collaboration mechanisms that the member associations have with the relevant government institutions, as well as with other NGOs. This presents an opportunity to sell the human security approach to both governments and collaborating NGOs.

(3) In many countries in the IPPFAR, there are several avenues for joint planning and implementation that exist between government and NGOs. IPPFAR can use this as a vehicle for operationalizing the human security approach. For example, in Liberia, there is NGO association, which is involved in a number of agenda setting forums amongst NGOs and between government and NGOs through which joint planning and implementation take place.

(4) In countries that are post conflict, there are local opportunities through which the IPPFAR member associations can access funding to operationalise some of the components of human security. In Liberia for example, during the years of conflict, many UN agencies and international NGOs lost their infrastructure in the country. Following the war, they chose to fund local NGOs which were more established in the community to implement their activities.

\subsubsection{Hindering factors}

(1) Capacity gaps. Specific areas for capacity development that were reported in the countries visited include; advocacy, proposal development and monitoring and evaluation. Further to this, NGOs and government will need their capacity built in the application of the human security approach. 
(2) Resource gaps are evident in almost all development efforts. In the IPPFAR member associations visited, there were serious financial challenges in implementing their programmes. For example, Family Planning Association of Liberia (FPAL) is still struggling to grow its capacity to what it was before the war. It currently can only afford to run 4 clinics, compared to the 32 that they were running before the war.

(3) Joint planning and implementation is a challenge. In the words of one respondent,

"You have to consider joint accountability and joint priorities. On the one hand, you have governments that are implementing, not based on what they should, but what they can. On the other hand, you have NGOs that are implementing according to their individual priorities. Though this is a challenge, it has been done, with varying degrees of success”.

\section{Conclusions}

From the study, there is adequate justification for IPPFAR to pursue the operationalization of human security approach to SRHR programming. The findings are clear on the potential benefits of this approach for furthering the goals of SRHR initiatives in line with the principles and guidelines expressed in the Maputo Plan of Action and the MDGs.

IPPFAR can narrow the concept of human security into a more analytically tractable concept that prioritizes certain human security components over others. From this study, economic security, community security and health security have the greatest impact on the reproductive health of the people. And since the components of human security are diverse and require different skill sets to implement, IPPFAR can harness opportunities for collaboration and corporation with partners that exist in the development community. However, for IPPFAR to succeed in its collaborating partnerships, it needs to ensure that all collaborating partners fully understand the human security approach. Thus, there is a need for an orientation of its member associations on this concept.

The key lessons learnt from this study are that effective use of family planning services mitigates the effects of other human insecurities including economic insecurity, food insecurity and health insecurity, as its application in the families will reduce family size and demand on available resources. Involving men in reproductive health activities, including family planning is crucial if such interventions are to be successful. In all the visited countries, men seem to have more influence in making family decisions, thus interfering with personal and economic securities of their spouses. On the other hand, the technical capacity of IPPFAR member associations cannot cope with human security in their programmes with the existing staffing levels and skills set.

\section{References:}

Democratic Republic of Congo. (2007). Poverty reduction and growth strategy paper 2006. International Monetary Fund, Washington D. C.

Government of Japan. (2008). TICAD IV Yokohama action plan. Tokyo International Conference on African Development IV. Retrieved from: http://www.mofa.go.jp/region/africa/ticad/ticad4/doc/actoin.pdf.

Government of Uganda. (2005). Poverty Eradication Action Plan (2004/5-2007/8). Ministry of Finance Planning and Economic Development.

Jolly, R. \& Deepayan, B. R.. (2007, May). Human security: National perspectives and global agendas—Insight from National Human Development Reports. Journal of International Development, 19(4), 457-472.

OECD. (2006). Volume 2: Working Document, Workshop on Human Security in West Africa: Challenges, Synergies and Action for a Regional Agenda, 26-28 March 2006. Lome, Togo. Governance, Conflicts Dynamics, Peace and Security Unit Sahel; West Africa Club/OECD.

(to be continued on Page 62) 